\title{
WASTE PYROLYSIS TIRE OIL AS ALTERNATIVE FUEL FOR DIESEL ENGINES
}

\section{TANMAY SONI ${ }^{1} \&$ ABHISHEK GAIKWAD ${ }^{2}$}

${ }^{I}$ Research Scholar, Department of Mechanical Engineering, Shepherd Institute of Engineering and Technology, Sam Higginbottom University of Agriculture, Technology and Sciences, Allahabad, Uttar Pradesh, India

${ }^{2}$ Assistant Professor, Department of Mechanical Engineering, Shepherd Institute of Engineering and Technology, Sam Higginbottom University of Agriculture, Technology and Sciences, Allahabad, Uttar Pradesh, India

\section{ABSTRACT}

Today, India is facing two biggest problems, one is the depletion of the fossil fuel reservoir and the other is the pollution. These two problems motivated us, as well as many other researchers, to work on the utilization of non biodegradable material. Scrap tyre consists of organic matter, that is often disposed illegally in open lands, ultimately causing an environmental problem. Pyrolysis is considered as a useful technique, for recycling of scrap tyres by using which liquid, gases, carbon black and steel wires are obtained. Tire-derived oils can be used as fuel or added to conventional fuels, producing fuel blends with improved properties and reduced cost. Pyrolysis of scrap tyre starts at $250{ }^{\circ} \mathrm{C}$ and gets completed at $550{ }^{\circ} \mathrm{C}$. The properties of the Tyre pyrolysis oil, was compared with the petroleum products and found that, it can also be used as a fuel for diesel engine. Experimental Investigations will examine the use of blended fuel (i.e., TPO with Pure Diesel), in different ratios in single cylinder, four stroke VCR diesel engines. Performance characteristics like Efficiencies and Powers were calculated at various loads conditions, at constant speed. It was found that, the blends of pyrolysis tire oil (TPO) of waste tire can efficiently be used in diesel engines, without any engine modifications.

KEY WORDS: Alternative Fuels, Blend, Tire Pyrolysis Oil, Engine Performance \& VCR Diesel Engine

Received: Sep 23, 2017; Accepted: Oct 13, 2017; Published: Nov 11, 2017; Paper Id.: IJMPERDDEC201730

\section{INTRODUCTION}

Currently fossil fuel crisis, is the major problem and in the coming years, its demand is going to increase tremendously. On the other side, waste disposal problem and environmental concern, is also a biggest challenge in front of scientist. These concerns force us to seek for new, clean and efficient waste-to-energy technologies. A waste-to-fuel technology, offers a very promising solution approach for both issues. The increasing demand of power powered vehicles, resulting in wide availability of scrap tires. About one billion waste tires are produced every year, over the globe [1]. Tire waste is a serious environmental problem, since they serve as breeding sites for mosquitoes and rodents, and feature large fire hazards [2]. Tires are difficult to deteriorate, pollute various ecosystems and causing damage to plant and wildlife. The disposal of scrap tires is a growing problem worldwide. Since they are artificial polymer and also not biodegradable material, hence it is considered as a serious pollution problem, in terms of waste disposal. Since, rubber from tires has high calorific value (35-40 MJ/kg) [3] and as well as, considerable amount of carbon black makes them a good feedstock for fuel production.

Pyrolysis represents an environmental friendly and efficient way, to transform solid wastes into fuels, with acceptable chemical and physical properties, for the use in the internal combustion engines. Pyrolysis of 
waste tire has been identified, as a promising alternative for removing scrap tires, from the environment [1, 4]. The pyrolysis process is based on breakdown of complex molecules, into simpler molecules by use of heat. The Tire Pyrolysis Oil (TPO) used here, was made by pyrolysis of waste tyres at $500^{\circ} \mathrm{C}$, in the absence of oxygen, with a hydrocarbon gas, carbon black and steel wire, as by products. The process produces gaseous, liquid (condensate) and solid fractions. Liquid phase can be used for power generation, in industry and as fuel in automotive engines, serving as unconventional fuel alternative, to the petroleum derivatives.

Many studies show that, the characteristics of the products obtained from the tires pyrolysis, differ by operating conditions such as temperature, pressure and residence time [5, 6, and 7]. Besides the environmental and sustainability benefits, tire pyrolysis must contribute economically, to generate cheaper fuels, if the process is deployed on a large scale.

\section{MATERIALDS AND PROCESS DESCRIPTION}

In the present study, TPO was extracted from large stock of waste tires using horizontal axis rotary type reactor, with a recycling capacity of 8 tons per batch. Before reaction process, waste tires were cut into a number of pieces and steel wires were removed. The process was carried out between $500^{\circ} \mathrm{C}$ and $550^{\circ} \mathrm{C}$. The products of pyrolysis, in the form of vapor were sent to a water cooled condenser and the condensed liquid was collected as a fuel.

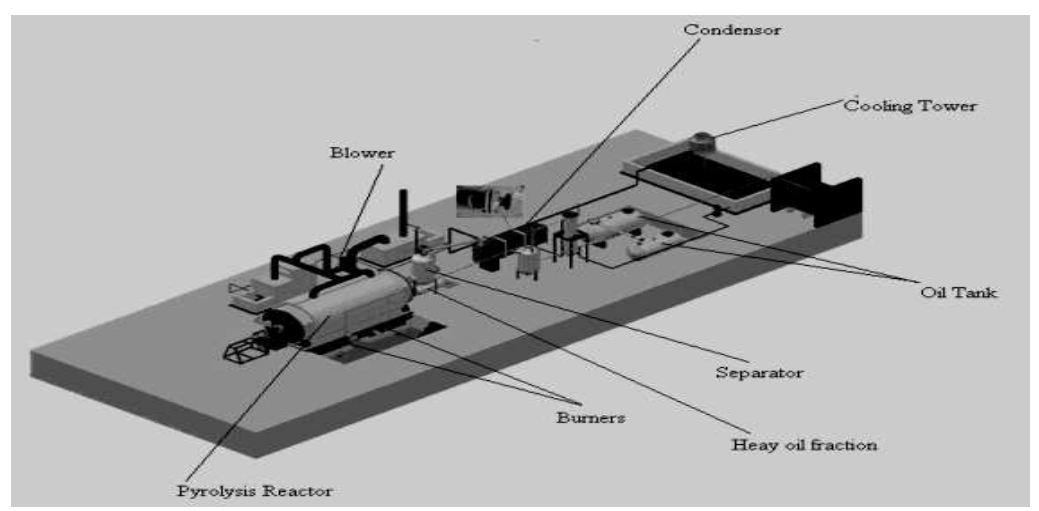

Figure1: Horizontal Axis Rotary type Pyrolysis Reactor

Table 1: Properties of Fuel

\begin{tabular}{|c|c|c|c|}
\hline Property & Units & Diesel & $\begin{array}{c}\text { Pyrolysis Tire } \\
\text { oil }\end{array}$ \\
\hline Chemical Formula & - & $\mathrm{C}_{12} \mathrm{H}_{26}$ & - \\
\hline Calorific Value & $\mathrm{KJ} / \mathrm{kg}$ & 43350 & 42840 \\
\hline Ignition delay period & $\mathrm{Sec}$ & 0.002 & - \\
\hline Colour & - & Red/Orange & Black \\
\hline Density at $15{ }^{\circ} \mathrm{C} \mathrm{kg} / \mathrm{m} 3$ & $\mathrm{Kg} / \mathrm{l}$ & 2.7 & 950 \\
\hline Total Fat in $100 \mathrm{~g}$ & $\%$ & 815 & 785.6 \\
\hline Kinematic Viscosity at $40^{\circ} \mathrm{c}$ (cst) & - & Nil & $6.52 \mathrm{cst}$ \\
\hline Cetane No. & - & $\begin{array}{c}47.0 \\
\text { Insoluble }\end{array}$ & $\begin{array}{c}62.8 \\
\text { Insoluble }\end{array}$ \\
\hline
\end{tabular}

\section{EXPERIMENTAL SETUP}

Computerized single cylinder, 4 strokes, direct injection, water cooled VCR (Variable Compression Ratio) Diesel Engine Test Rig is used. An engine indicator is fitted in control panel, which sense pressure and crank angle data interface with computer. The engine and Dynamometer was interfaced to a control panel. 
Performance Analysis Software "IC Engine Soft Ver. 9.0 Supplied by test rig supplier" Apex Innovation Pvt Ltd", was used for recording the test parameter engine power, such as Indicated Power, Brake Power, Friction Power, Break thermal Efficiency and Indicated Thermal Efficiency. The Calorific Value and Density of pyrolysis tire oil after testing were recorded as $42840 \mathrm{kcal} / \mathrm{kg}$ and 950 respectively. Engine is operated at three different load condition i.e., no load, 50\% load, and at full load (i.e., $0 \mathrm{~kg}, 4 \mathrm{~kg}$ and $8 \mathrm{~kg}$ respectively). The error in load of $+0.30 \mathrm{~kg}$ is considered. Blends of TPO $(10 \%$ and $20 \%)$ with Diesel were tested at three different load conditions for performance characteristics. Results of these blends were calculated and recorded and were compared with pure diesel. The entire tests have been performed in IC Engine lab at Moradabad Institute of Technology, Ram Ganga Vihar, Phase II, Moradabad, Uttar Pradesh (India).

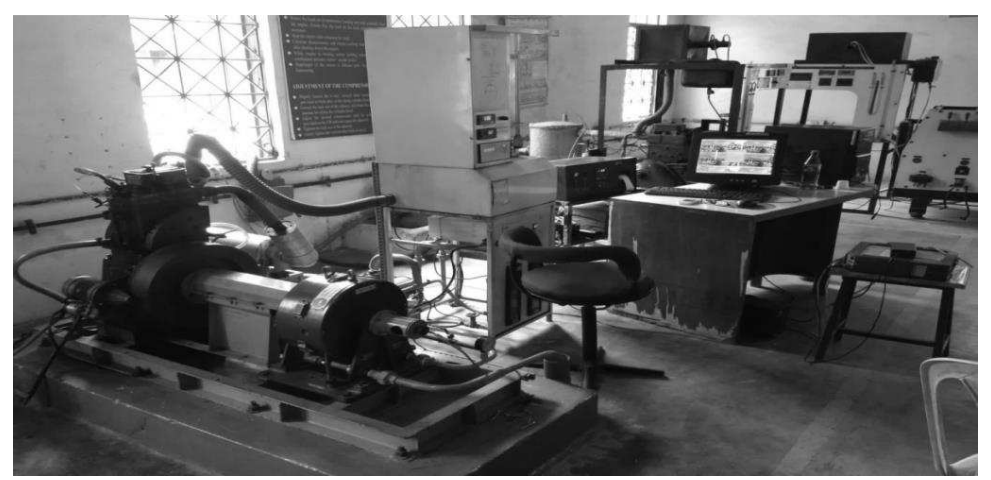

Figure 2: VCR Single Cylinder 4-S Engine Setup

Table 2: Specifications of Test Rig

\begin{tabular}{|l|l|}
\hline \multicolumn{1}{|c|}{ Make and Model } & Kirloskar-Oil Engine Limited \\
\hline Engine Type & 4 stroke, water cooled (TUI) \\
\hline Number of Cylinder & Single \\
\hline Bore & $87.5 \mathrm{~mm}$ \\
\hline Stroke & $110 \mathrm{~mm}$ \\
\hline Cubic Capacity & $661 \mathrm{Cc}$ ( 0.661liter) \\
\hline Net Power & $3.50 \mathrm{kw} \mathrm{@} \mathrm{1500} \mathrm{rpm}$ \\
\hline Compression ratio & 12 to $18: 1$ \\
\hline Max Speed & $1500 \mathrm{rpm}$ \\
\hline Valves per Cylinder & Two \\
\hline Number of nozzles & One (1) \\
\hline Fuel injection type & Direct Injection \\
\hline Max power & $5.2 \mathrm{kw}$ \\
\hline Connecting rod length & $234 \mathrm{~mm}$ \\
\hline Orifice Diameter & $20 \mathrm{~mm}$ \\
\hline Dynamometer arm length & $185 \mathrm{~mm}$ \\
\hline Rota meter & $2(\mathrm{engine}$ and calorimeter $)$ \\
\hline
\end{tabular}

\section{Preparation of Blends}

Tire Pyrolysis oil at two different compositions was blended with diesel, using handmade technique. Pyrolysis tyre oil is blended in $10 \%$ and $20 \%$, with pure diesel to prepare $500 \mathrm{ml}$ of blended fuel at a time. These blends are termed as TPO10 and TPO20. The percentage ratios of pyrolysis tyre oil and Diesel in blends are: 


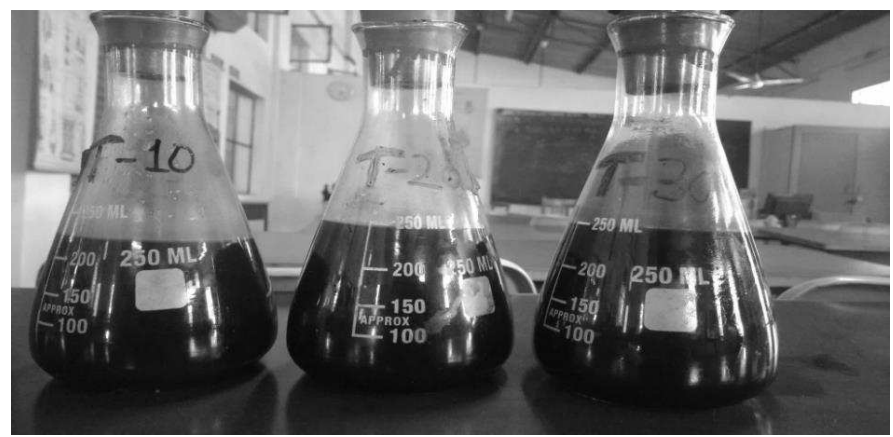

Figure 3: Fuel Blends of Pyrolysis Plastic Oil and Diesel Oil

\section{EXPERIMENTAL PROCEDURE}

- First Switch on power supply.

- Check water supply connections to engine and dynamo meter, through rota meter.

- On fuel supply, if separate arrangement is done for storage \& supply of biodiesel.

- The engine is started and warm up for 20 minutes.

- Start the computer and select the mode (configure) to enter the data.

- Select the run option.

- Each test is conducted and data is stored at five different loads, as on 0, 4, 8 load.

- Engine is run for 10-25 minute for one test and data available is stored by log key at the

- End of time interval.

- Next tests are conducted in sequence like pure diesel, T10\%\& T20\%.

\section{CALCULATION OF ENGINE EFFICIENCY}

Efficiency is the relation between the power delivered and the power that could be obtained if the engine operates without loss of power. Depending upon whether it is brake power or indicated power the terms break thermal efficiency or indicated thermal efficiency is used.

$$
\begin{aligned}
& \boldsymbol{y b t h}=\frac{b p}{m f Q f} \\
& \text { yith }=\frac{i p}{\mathrm{mf} Q f}
\end{aligned}
$$

Where $\mathrm{m}_{\mathrm{f}}=$ Fuel mass flow rate

$\mathrm{Q}_{\mathrm{f}}=$ Calorific value of fuel

$$
\begin{aligned}
& I p=\frac{\text { PimLAnk }}{60000} k w \\
& B p=\frac{2 \pi R F N}{60000} k w \\
& F p=I p-B p k w
\end{aligned}
$$




$$
\begin{aligned}
& \mathrm{P}_{\mathrm{im}}=\text { indicated mean effective pressure, } \\
& \mathrm{L}=\text { length of the stroke } \\
& \mathrm{A}=\text { area of the piston, } \\
& \mathrm{n}=\text { number of power strokes per minute } \\
& \mathrm{K}=\text { number of cylinders, } \\
& \mathrm{R}=\text { length of moment arm, } \\
& \mathrm{F}=\text { force }
\end{aligned}
$$

$\mathrm{N}=$ speed in revolutions per minute.

Table 3: Engine Efficiency at Different Load Conditions For Pure Diesel

\begin{tabular}{|c|c|c|c|}
\hline Speed (rpm) & Load (kg) & $\boldsymbol{\eta}_{\text {Ith }}$ Eff (\%) & $\boldsymbol{\eta}_{\text {Bth }}$ Eff (\%) \\
\hline 1482.00 & 0.38 & 94.73 & 1.83 \\
\hline 1477.00 & 4.07 & 72.46 & 15.13 \\
\hline 1458.00 & 8.26 & 66.15 & 24.63 \\
\hline
\end{tabular}

Table 4: Engine Efficiency At Different Load Conditions For T10

\begin{tabular}{|c|c|c|c|}
\hline Speed (rpm) & Load (kg) & $\boldsymbol{\eta}_{\text {Ith }}$ Eff (\%) & $\boldsymbol{\eta}_{\text {Bth }}$ Eff (\%) \\
\hline 1530.00 & 0.36 & 51.54 & 2.55 \\
\hline 1528.00 & 4.27 & 58.12 & 21.32 \\
\hline 1509.00 & 8.26 & 51.89 & 31.34 \\
\hline
\end{tabular}

Table 5: Engine Efficiency at Different Load Conditions for T20

\begin{tabular}{|c|c|c|c|}
\hline Speed (rpm) & Load (kg) & $\boldsymbol{\eta}_{\text {Ith }}$ Eff (\%) & $\boldsymbol{\eta}_{\text {Bth }}$ Eff (\%) \\
\hline 1526.00 & 0.42 & 56.38 & 3.53 \\
\hline 1500.00 & 4.41 & 53.52 & 21.63 \\
\hline 1536.00 & 8.39 & 49.84 & 30.09 \\
\hline
\end{tabular}

Table 6: Engine Power at Different Load Conditions for Pure Diesel

\begin{tabular}{|c|c|c|c|c|c|}
\hline Speed (Rpm) & Load (Kg) & IP (Kw) & BP (Kw) & FP (Kw) & FP Loss in (\%) \\
\hline 1482.00 & 0.38 & 5.50 & 0.11 & 5.39 & 98.0 \\
\hline 1477.00 & 4.07 & 5.47 & 1.14 & 4.33 & 79.2 \\
\hline 1458.00 & 8.26 & 6.15 & 2.29 & 3.86 & 62.8 \\
\hline
\end{tabular}

Table 7: Engine Power at Different Load Conditions for T10

\begin{tabular}{|c|c|c|c|c|c|}
\hline Speed $(\mathbf{R p m})$ & Load $(\mathbf{K g})$ & IP $(\mathbf{K w})$ & BP $(\mathbf{K w})$ & FP $(\mathbf{K w})$ & FP Loss in $(\%)$ \\
\hline 1530.00 & 0.36 & 2.10 & 0.10 & 1.99 & 94.8 \\
\hline 1528.00 & 4.27 & 3.38 & 1.24 & 2.14 & 63.3 \\
\hline 1509.00 & 8.26 & 3.92 & 2.37 & 1.55 & 39.5 \\
\hline
\end{tabular}

Table 8: Engine Power at Different Load Conditions for T20

\begin{tabular}{|c|c|c|c|c|c|}
\hline Speed $(\mathbf{R p m})$ & Load $(\mathbf{K g})$ & IP $(\mathbf{K w})$ & BP $(\mathbf{K w})$ & $\mathbf{F P}(\mathbf{K w})$ & FP Loss In \% \\
\hline 1526.00 & 0.42 & 1.97 & 0.12 & 1.84 & 93.4 \\
\hline 1500.00 & 4.41 & 3.11 & 1.26 & 1.85 & 59.4 \\
\hline 1536.00 & 8.39 & 4.05 & 2.45 & 1.61 & 39.8 \\
\hline
\end{tabular}




\section{RESULT AND DISCUSSIONS}

Indicated Power for Pure Diesel is maximum at all loads conditions. The indicated power of TPO10 and TPO20 is very less compared to Pure Diesel. The power available at the crankshaft to do work i.e., BP for TPO10 and TPO20 is very close to Pure Diesel. It starts increasing after the few minutes of continuous running of engine. Figure 4 is showing that the power produced by TPO10 and TPO20 is quite low compared to Pure Diesel but Figure 5 shows that Brake Power for TPO10 and TPO20 at different load conditions is higher than Pure Diesel. The conclusion of the above statements is described in Figure 6 which shows that the frictional losses of TPO10 and TPO20 are vey less in comparison to Pure Diesel. Frictional losses reduce at higher loads. Lower \% of frictional losses makes the tyre pyrolysis oil, suitable for future as an alternative fuel.

It was noticed that, indicated thermal efficiency for Pure Diesel is maximum, at all loads conditions. The indicated thermal efficiency of TPO10 and TPO20, at half load condition is close to Pure Diesel values. Pure Diesel has the lowest brake thermal efficiency, available at different load conditions comparing with TPO10 and TPO20.

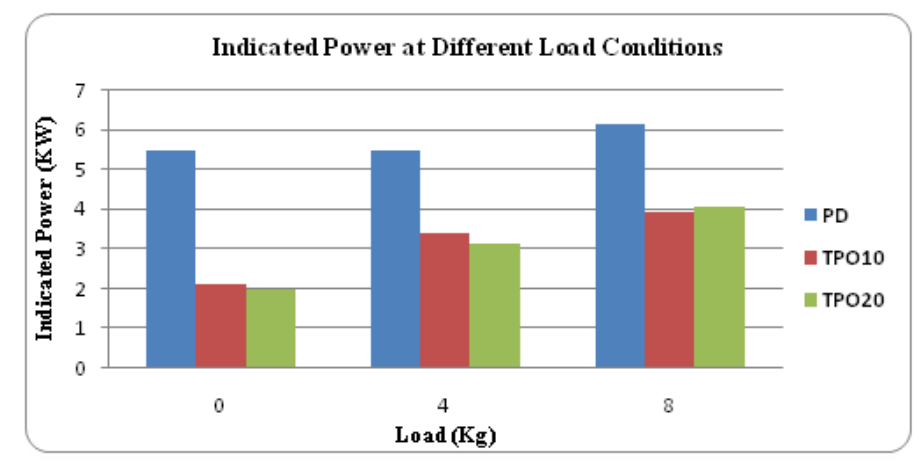

Figure 4: Graphical Representation of Engine Indicated Power

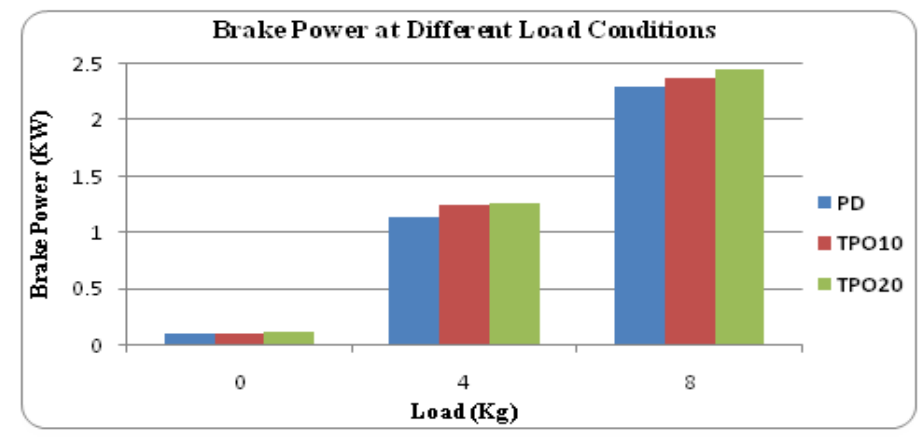

Figure 5: Graphical Representation of Engine Brake Power

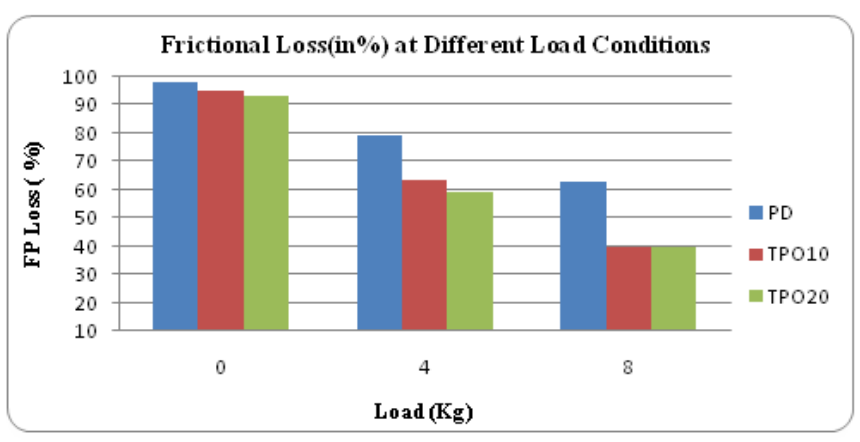

Figure 6: Graphical Representation of Frictional Loss 


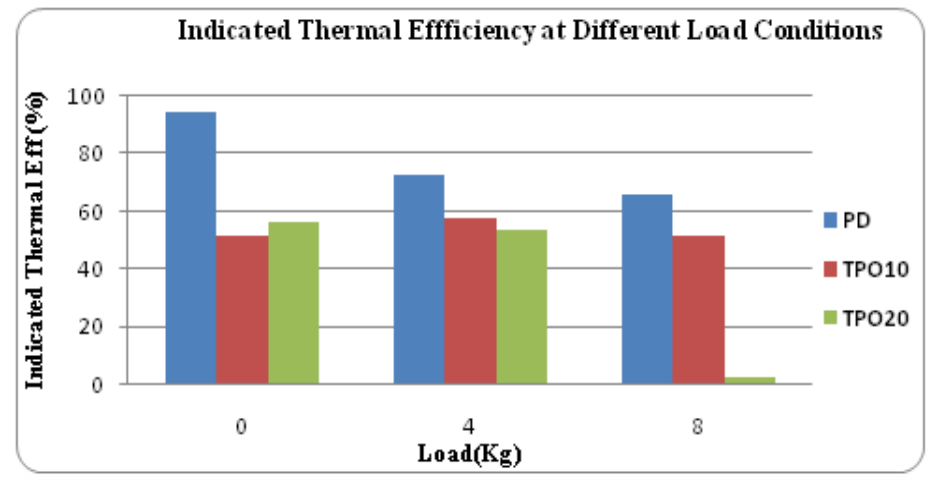

Figure 7: Graphical Representation of Indicated Thermal Efficiency

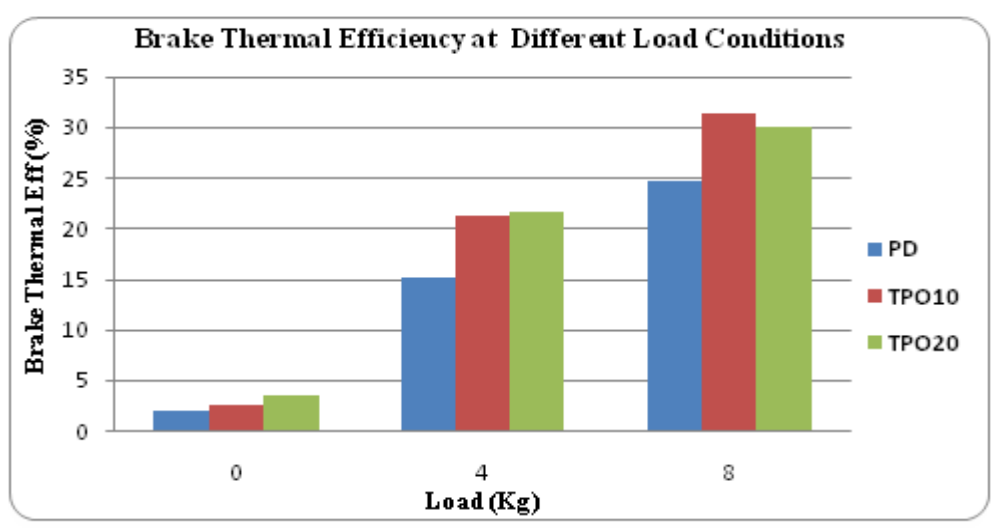

Figure 8: Graphical Representation of Brake Thermal Efficiency

\section{CONCLUSIONS}

The results obtained, show the high potential of tyre pyrolysis oil, being used in various fields. The different grades of oil obtained after distillation, increases its commercial value. Although, some TPO plants have come up, only 20 $-25 \%$ of scrap tyres are being recycled, by this process. As a result, scrap tyres won't be disposed of into the environment in form of landfills or wastes; rather they will be properly processed and converted to useful products. The fact that, pyrolysis of waste tyres is considered to be a useful solution, to protect the environment, it can also be made available with low cost.

TPO10 and TPO20, results were very satisfied and can be used as an alternative fuel, after evaluating few more properties and emissions. Brake Power for TPO20 is better than Pure Diesel and TPO10, and overall results also states that, $20 \%$ of tyre pyrolysis oil can be blended with diesel for better results, at cheaper costs. In future, higher ratio of TPO can also be examined.

\section{REFERENCES}

1. Ilkulic C, Aydin H. Fuel production from waste vehicle tires by catalytic pyrolysis and its application in a diesel engine. Fuel Process Technology 2011; 92:1129-35.

2. Wójtowicz MA, Serio MA. Pyrolysis of scrap tires: can it be profitable? ChemTech 1996(October).

3. Martinez JD, Rodriguez-Fernandez J, Sanchez-Valdepenas J, Murillo R, Garcia T. Performance and emissions of an automotive diesel engine using a tire pyrolysis liquid blend. Fuel 2014;115: 490-9. 
4. Murugan S, Ramaswamy MC, Nagarajan G. Assessment of pyrolysis oil as an energy source for diesel engines. Fuel Process Technology 2009; 90:67-74.

5. Banar M, Akyildiz V, Ozkan A, Çokaygil Z, Onay O. Characterization of pyrolytic oil obtained from pyrolysis of TDF (Tire Derived Fuel). Energy Convers Manage 2012; 62: 22-30.

6. Fernandez A M, Barriocanal C, Alvarez R. Pyrolysis of a waste from the grinding of scrap tyres. J Hazard Mater 2012; 203204:236-43.

7. Gaikwad. A., Singh, A., Kumar, A., Tiwari, A., 2014. Investigation and comparison of performance characteristics of single cylinder, $4_{-}(V C R)$ diesel engine using soybean refined oil as blend with pure diesel. Volume 5, Issue 4, April, pp. 224-233.

8. Gaikwad. A., Kumar, A., Singh, A., Kumar, A., 2014. Investigation and comparison of performance characteristics of single cylinder, $4_{-}(V C R)$ diesel engine using sun flower refined oil as blend with pure diesel. Volume 5, Issue 2, March - April (2014), pp. 25-35. 